\title{
Operational optimization at signalized metering roundabouts using cuckoo search/local search algorithm
}

\author{
Hong Ki An ${ }^{1 *}$, Yao Liu ${ }^{2}$ and Dong Sun Kim ${ }^{3}$, \\ 1 Faculty of Transportation Engineering, Huaiyin Institute of Technology, Huai'an, China; \\ hong_ki.an@mymail.unisa.edu.au \\ 2 Faculty of Engineering Management, Huaiyin Institute of Technology, Huai'an, China; \\ xiaoyao_6554@163.com \\ 3 Department of Urban and Realty Engineering, Daejin University, Gyeonggi, Korea; kimdns@daejin.ac.kr \\ * Correspondence: hong_ki.an@mymail.unisa.edu.au; Tel.: +8229652855
}

\begin{abstract}
A metering roundabout where traffic is controlled by traffic lights with phase times influenced by queue detector occupancy might be the solution to enhance performance when there are unbalanced traffic flows at roundabouts. There have, however, been minimal studies on how the distance of the queue detector from the stop line affects signal phase time durations and the queuing lengths. This research, therefore, seeks to develop a Cuckoo Search/Local search Algorithm using parameters such as arrival volumes, conflicting volumes, detector distance and phase time to investigate the relationship of signal setting, detector location and queuing formulations. Also, some additional statistical tests were performed for the fitness of the data. In order to conduct solid model validations, model output data was compared against the AIMSUN model. The results from the analyses demonstrated that the queue detector distance can affect phase time durations and vehicle queuing lengths on the controlling approach as well as queuing lengths on the metered approach. This study showed that, based on the study for the Old Belair Road roundabout in Adelaide, South Australia, the total queue length (controlling + metered) will be minimized when the detector is relocated at 209 meters from the roundabout stop line, giving longer phase green times and resulting in decreased intersection queuing lengths.
\end{abstract}

Keywords: Metering roundabout, Detector location, AIMSUN, Cucksoo search/Local search algorithm

\section{Introduction}

Roundabouts can experience congestion problems, particularly during peak hours when there are unbalanced traffic conditions [1-5]. Delays on one or two approaches can be observed because entering vehicles may be interrupted by rotating vehicles. Thus, in order to form balanced traffic flow conditions and obtain enough gaps between rotating vehicles, the signalized roundabout emerged as a popular alternative, often called a metering roundabout.

Several researchers attempted to make a definition of unbalanced traffic conditions using the origin-destination factor, which is able to enhance metering roundabout capacity [6,7]. According to past studies, the operational performance on a roundabout can be exacerbated by unbalanced traffic conditions. In such cases, an effective solution is the metering roundabout leading to a decrease in queues or delays. In addition, past studies explained that vehicle movements on a roundabout and T-junction are similar and they operate individually. Another studies $[7,8]$, however, gave a definition with respect to unbalanced conditions with the prerequisite that ingression vehicles from one approach might affect the vehicle movements on other approaches at roundabouts. According to Akçelik $[9,10]$, the distance of the queue detector from the give-way line should be in the range of 50 
- 120 meters using the probability of the blockage parameter that is used when a road has limited queue storage. The parameter describes how downstream traffic flow affects upstream congestions.

Fortuijn [11], a study of the queue detector distance from the stop line is important because signal phase durations are greatly influenced by detector occupancy rates with respect to the metering roundabout. Fortuijn [11], also tried to find the queue detector distance (demand detector) using the Pollaczek-Khinchine M/M/1 waiting-time formula. However, this study was based on a different type of control metering roundabout which had the queue detector installed on the dominant approach and a delay detector on the sub-dominant approach.

Sergey et al. [12] analyzed the associated characteristics of traffic signal control and dynamic guidance systems, using intelligent technology and fusion technology to study its intelligent collaboration, and proposed a structural framework for urban traffic signal control and traffic guidance system intelligent collaboration, which is controlled by traffic signals. Hao et al. [13] discussed the problem of traffic demand balance under the condition of limited environmental capacity of road sections using mathematical programming methods to describe the continuous network balance problem of demand changes in the waiting situation. However, the impact of urban traffic signals on the passage capacity of road sections and environmental pollution at intersections and how to meet the increasing traffic demand by increasing the traffic demand of the entire network was not considered.

Brederode and Verlinden [14] considered how to increase network traffic demand under traffic signal control conditions. Lin et al. [15] studied the user balance distribution problem and the system optimal distribution problem based on emissions. Ding et al. [16] discussed the generalized user optimal equilibrium assignment problem and the generalized system optimal equilibrium assignment problem. However, the determination of the user balance allocation model considered the problem of continuous balance network design. Fontaine and Minner [17] combined the road environment capacity limitation, the optimal traffic signal setting problem and the urban traffic discrete network design problem. However, the construction of new road sections maximizes the traffic demand to meet the growing traffic demand in the city and the maximum demand of the transportation network can meet the requirements of modern urban environmental protection through the restriction of road environmental capacity.

At present, many researches on the optimization and control of urban traffic are mostly based on the optimization of traffic flow distribution in the urban transportation network, or the optimal control based on the shortest time between the traveler's starting points, or the largest urban capacity. Optimal control of traffic flow distribution optimizes for the signal period or signal time interval mostly using conventional optimization methods, such as the genetic algorithm, particle swarm optimization, adaptive neuro fuzzy method, etc [18-20]. Therefore, there are still relatively little research to investigate detector locations, which is an important parameter affecting the entire performance of the roundabout.

This study investigates the optimal signal operational using Cuckoo Search/Local search Algorithm. The detail of detector locations and the queuing length on major (controlling) approach and minor (metered) approach presented in detail. The proposed method simulated using Matlab software and compared with microscopic simulation model AIMSUN. To achieve this purpose, drone footage data will be used in the process of CS/LS algorithm, and AIMSUN model development, calibration and validation. The result shows that the metering roundabout can reduce the queues of the major (controlling) approach. However, the queuing length on the minor approach (metered) would be longer due to the red signal blocking vehicles from entering. Furthermore, Geoff E. Havers (GEH) tests will be performed to assess the fitness of the model in AIMSUN. 


\section{Research background}

\subsection{The Metering Roundabouts Model}

The concept of metering roundabout is described in Figure 1. In this roundabout, detectors are installed on the controlling (dominant) approach and the traffic signals on the metered (subdominant) approach are differently set up from traditional ones.

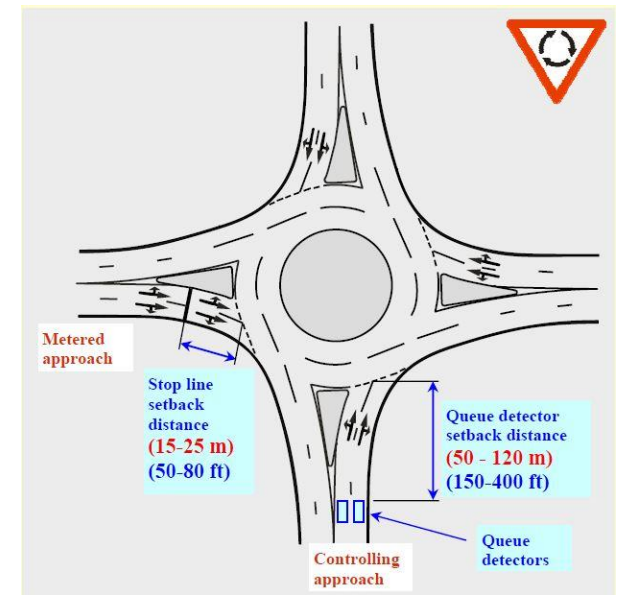

Figure 1. Concept of metering roundabout [10].

Stevens [1], Azhar and Svante [21], and Mosslemi [22] mentioned that a signal roundabout can be grouped into three categories: traffic flow control, operation time and number of approaches controlled as presented in Table 1.

Table 1. Categories of signal roundabout.

\begin{tabular}{|c|c|c|}
\hline Classification & Control Type & Description \\
\hline \multirow{2}{*}{ Traffic flow control } & Direct control & $\begin{array}{l}\text { Entering traffic flow and circulatory traffic flows } \\
\text { are controlled by signals }\end{array}$ \\
\hline & Indirect control & $\begin{array}{l}\text { Only entering traffic flows are controlled by } \\
\text { signals }\end{array}$ \\
\hline \multirow{2}{*}{ Operation time } & Full time control & Signal is operated for 24 hours \\
\hline & Part time control & Signal is activated by time of day or by detectors \\
\hline \multirow[b]{2}{*}{$\begin{array}{l}\text { Number of approaches } \\
\text { controlled }\end{array}$} & Full control & All approaches are controlled by signals \\
\hline & Partial control & $\begin{array}{l}\text { Approaches are controlled by signals while the } \\
\text { remaining approaches operate under give way } \\
\text { control }\end{array}$ \\
\hline
\end{tabular}

Among the categories of signal roundabouts given in the table above, unbalanced traffic flow conditions usually occur during peak hours, thus, indirect with part-time control is the most appropriate control system $[1,3,7,9]$. In addition, the simple form of a signal metering roundabout has a valuable benefit-cost ratio because it is easy to operate with low installation cost [23].

It is also the case that the metering signal phase lengths can be determined by the position of the approach detector. An et al. [24] applied the concept and formulated the queuing length models at metering roundabouts in order to estimate the queuing length based on detector locations and signal phase times. In their study numerical models were formulated with six main parameters that significantly affect the formation of queuing length for each approach. Three variables (i.e. arrival volume, conflict volume and vehicle space) commonly have a positive relationship to queuing length. However, detector location on the controlling and metered approaches, vehicle presence time on the controlling and metered approaches, and signal phase green and red time duration can be differently 
applied. Therefore, the queuing length estimation model in controlling and metered approaches can be expressed in Equation 1 and 2 [24].

$$
\begin{gathered}
Q_{c o n}=\frac{\left(\frac{P_{\text {gre }}}{T} \times \frac{\frac{V_{i}}{N L}}{T} \times \frac{V C_{i}}{T L} \times D L_{C} \times P T_{C} \times V S\right)}{D L_{M} \times P T_{M}} \times 6700 \\
Q_{\text {met }}=\frac{\left(\frac{P_{r e d}}{T} \times \frac{\frac{V_{i}}{N L}}{T} \times \frac{V C_{i}}{N L} \times D L_{M} \times P T_{M} \times V S\right)}{D L_{C} \times P T_{C}} \times 15000
\end{gathered}
$$

The phase green and red times can vary theoretically by up to 300 seconds ( 5 minutes). To explain in detail, in a cycle of 300 seconds, the green and red time may take a share of the cycle time. Thus, a relationship between Pred and Pgre is presented in Equation 3.

$$
P_{\text {red }}=300-P_{\text {gre }}
$$

Where Qcon is the queuing length of the controlling approach (m), Qmet is the queuing length of the metered approach (m), Pgre is the green time (s), Pred is the red time (s), NL is the number of the lane, Vi is the arrival volume of subject $\mathrm{i}$ approach (vehs), Vci is the conflict volume against subject $\mathrm{i}$ approach, DLc is the detector location on the controlling approach $(\mathrm{km})$, DLM is the detector location on the metered approach $(\mathrm{km}), \mathrm{VS}$ is the vehicle space $(\mathrm{m}), \mathrm{PTc}$ is the vehicle presence time on the Detector C (s), РTM is the vehicle presence time on the Detector M (s), and T is time.

The Old Belair Road roundabout has no detector on the metered approach, thus, constant " 1 " was applied for the cases (i.e. DLM $=1$ and PTM $=1$ ).

\subsection{The Cuckoo Algorithm}

The Cuckoo Search (CS) algorithm is an emerging algorithm that combines the common cuckoo breeding mechanism with the local search (LS) method $[25,26,27]$. The CS algorithm has a good initial search ability, but poor optimization ability in the later periods, low search accuracy and slow convergence speed, so it needs to be improved for multi-objective optimization.

For a 1-dimensional optimization problem, $\mathrm{d}$ variables are needed:

$$
x=\left[x_{1}, x_{2}, \ldots ., x_{d}\right]
$$

The Levy Flight location update formula is :

$$
\begin{gathered}
x_{i}^{t+1}=x_{i}^{t}+\alpha \oplus L(\lambda) \quad i=(1,2, \ldots n) \\
L(\lambda) \sim u=t^{-\lambda}, \quad 1<\lambda \leq 3
\end{gathered}
$$

Where: $x_{i}^{t+1}$ is the updated bird's nest position; $x_{i}^{t} \mathrm{t}$ is the current bird's nest position; $\oplus$ is the point-to-point multiplication; $\alpha$ is the step size; $L(\lambda)$ is the search path; $u$ is the standard normal variable and $u$ follows the normal distribution of $N\left(0, \sigma_{u}^{2}\right)$.

If the parasitic nest's communication threshold is $\delta$, the current optimal parasitic nest position is $x_{b}^{t}$ and the probability of parasitic nest $i$ to communicate is $p_{i}$. If $p_{i}<\delta$, then the communication in Equation 7 is performed.

$$
x_{i}^{t}=r \cdot x_{i}^{t}+(1-r) \cdot x_{b}^{t}, \quad i=1,2, \ldots, n
$$


In the formula: $x_{i}^{t}$ is the bird's nest position after communication; $r$ is a random number between $(0,1)$. When the CS algorithm parameters are set, it is found that the probability $p_{a}$ and the step size $\alpha$ are fixed, which will cause the algorithm's convergence and search speed to deteriorate. When setting the two, if $p_{a}$ is small and $\alpha$ is large, it will increase the number of iterations. If $p_{a}$ is large and $\alpha$ is small, it will improve the convergence speed, but the optimization ability is poor. Therefore, setting the two as dynamic quantities causes change with the number of iterations, which can both improve the convergence speed of the algorithm and increase its search accuracy. The specific improvement formula is as follows:

$$
\begin{gathered}
p_{a}(t)=p_{a, \max }-\frac{t}{g}\left(p_{a, \max }-p_{a, \min }\right) \\
\alpha(t)=\alpha_{\text {max }} \exp (c . t) \\
c=\frac{1}{g} \ln \left(\frac{\alpha_{\min }}{\alpha_{\max }}\right)
\end{gathered}
$$

Where: $p_{a}(t)$ is the probability function of discovery; $\alpha(t)$ is the step function; $\mathrm{c}$ is the intermediate variable; $p_{a, \max }, p_{a, \min }$ are the control parameters of $p_{a} ; \mathrm{g}$ is the number of iterations ; $t$ is the current evolution algebra; $\alpha_{\max }, \alpha_{\min }$ are the control parameters of the step size, respectively.

For the minimization of multi-objective problems, if the solution vector, $\boldsymbol{x}_{\mathbf{1}}, \boldsymbol{x}_{\mathbf{2}}$ satisfy Equation 11, then $\boldsymbol{x}_{\mathbf{1}}$ dominates $\boldsymbol{x}_{\mathbf{2}}$ :

$$
\begin{aligned}
& \forall_{i} \in\{1,2, \ldots, M\}: f_{i}\left(x_{1}\right) \leq f_{i}\left(x_{2}\right) \\
& \exists_{i} \in\{1,2, \ldots, M\}: f_{i}\left(x_{1}\right) \leq f_{i}\left(x_{2}\right)
\end{aligned}
$$

Where $M$ is the number of solution vectors; $f_{i}\left(x_{1}\right), f_{j}\left(x_{1}\right)$ are the minimum objective function values; $f_{i}\left(x_{2}\right), f_{j}\left(x_{2}\right)$ are the maximum objective function values.

After the optimal solution is generated, the optimal satisfactory solution is calculated using the CS algorithm which provides the optimal detector location and signal solution for the roundabout. The satisfaction of the objective function is in Equation 13.

$$
\mu_{i}=\left\{\begin{array}{cc}
1 & f_{i} \leq f_{i, \min } \\
\frac{f_{i, \max }-f_{i}}{f_{i, \max }-f_{i, \min }} & f_{i, \min }<f_{i}<f_{i, \max } \\
0 & f_{i} \geq f_{i, \max }
\end{array}\right.
$$

Where $\mu^{k}$ represents the satisfaction of the $i$-th optimal solution; $f_{i}$ is the $i$-th objective function value; $f_{i, \min }, f_{i, \max }$ are the minimum and maximum objective function values, respectively.

\subsection{The Local Search}

In order to improve the solution quality, a LS scheme was carried out, in which it explored the area less congested in the current archive which may obtain more non-dominated solutions [28,29]. The general operation of the scheme is described in the following steps.

Step 1: It began with a randomly selected point $\left(x_{m} \in R_{n}\right) \in E^{t}$, and the set step lengths $\Delta x_{i}$ in all of the organized directions $u_{i}, i=1, \ldots, n$. Setting $m=0$, and that $m$ was the size of $E^{t}$.

Step 2: Setting the beginning of the counter $m=m+1$, and $h=1$ where $h$ is the number of trials $\left(h=1, \ldots, h_{\max }\right)$ to obtain a more preferred solution than $x_{m}$.

Step 3: The variable $x_{i}$ was perturbed around the present temporary base point $x_{m}$ to get the new provisional base point $x_{m}^{\prime}$ as: 


$$
x_{m}^{\prime}=\left\{\begin{array}{lr}
x_{m}-\Delta x_{i} u_{i} & \text { if } f^{-}(*)>\left(f(*) \cap f^{+}(*)\right) \\
x_{m} & \text { if } f(*)>\left(f^{-}(*) \cap f^{+}(*)\right) \\
x_{m}+\Delta x_{i} u_{i} & \text { Else if } f^{+}(*)>f(*)
\end{array}\right.
$$

$$
\forall_{0} i=1,2, \ldots \ldots, n
$$

Where, $f(*)=f\left(X_{m}\right), f^{+}(*)=f\left(X_{m}+\Delta x_{i} u_{i}\right)$, and $f^{-}(*)=f\left(X_{m}-\Delta x_{i} u_{i}\right)$. Besides, $f(*$ ) was assumed as the valuation of the objective functions at a point.

Step 4: The condition of point $X_{m}$ was unchanged.

Although the number of trials $h$ was not satisfied, the step length $\Delta x i$ was decreased by using the next dynamic equation,

$$
\Delta x_{i}=\Delta x_{i}\left(1-(r)^{h / h_{\max }}\right.
$$

Where, $r$ is a random number, and $r \in[0,1]$, then, step 3 was repeated.

Step 5: Or else, if $x_{m}^{\prime}$ was preferred than, $x_{m}$ (i.e., $f\left(x_{m}^{\prime}\right)>f\left(x_{m}\right)$ then, the new base point would be $x_{m}^{\prime}$, hence, step 6 must be repeated.

Step 6: Also, it can be aided by the base points $x_{m}$ and $x_{m}^{\prime}$, in establishing a pattern direction $S$, as follows:

$$
S=x_{m}^{\prime}-x_{m}
$$

Point $x_{m}^{\prime \prime}$ had to be identified.

$$
x_{m}^{\prime \prime}=x_{m}^{\prime}+\lambda S
$$

Where, $\lambda$ is the step length, which could be taken as $\lambda=1$.

Step 7: If $f\left(x_{m}^{\prime \prime}\right) \leq f\left(x_{m}^{\prime}\right)$ set $x_{m}=x_{m}^{\prime}$, then step 4 had to be repeated.

Step 8: Or else, if $f\left(x_{m}^{\prime \prime}\right)>f\left(x_{m}^{\prime}\right)$, set $x_{m}=x_{m}^{\prime}, x_{m}^{\prime}=x_{m}^{\prime \prime}$, then, step 6 had to be repeated.

Step 9: If the $x_{m}$ had been the best possible points, they must be compared with predefined parameters to get to the end.

\section{Data collection}

Data collection for one hour during peak period was carried out at Old Belair Road roundabout in Adelaide, Australia for three days as below:

- $1^{\text {st }}$ survey: October 7, 2015 between 07:45 and 08:45 (Wednesday)

- $2^{\text {nd }}$ survey: October 8, 2015 between 07:25 and 08:25 (Thursday)

- $3^{\text {rd }}$ survey: November 17, 2015 between 07:50 and 08:50 (Tuesday)

There are six major parameters for calculating queuing length on each approach, and data were collected from three sources: field survey using drones, Sydney Coordinated Adaptive Traffic System (SCATS) and DPTI documents, as presented in Table 2.

For traffic volumes and signal phase time data, SCATS data were used. The SCATS, developed in Australia, is now used internationally as an adaptive traffic signal control [30]. SCATS obtains traffic information from detectors located behind the stop line on each lane. Traffic data information from SCATS includes two types, traffic count data and traffic signal operation data. All these counts are detector based, further, this data is stored in a NEXUS database managed by DPTI at the Barbara Hardy Institute, University of South Australia, and the use of historical data is also available [31]. SCATS VS data can be extracted from a selected period of a minimum of five minutes using Traffic Reporter.

Table 2. Collected data.

\begin{tabular}{lllllllll}
\hline \multicolumn{10}{c}{ October 7th } \\
\hline \multicolumn{10}{c}{ North(metered) approach } & \multicolumn{2}{c}{ South(controlling) approach } & \multicolumn{2}{c}{ Phase time } \\
\hline Time & VCN & V $_{\mathrm{N}}$ & Queue & VCS & Vs & Queue & Pgre & Pred \\
\hline $07: 45-07: 50$ & $5 \mathrm{veh}$ & $52 \mathrm{veh}$ & $600 \mathrm{~m}$ & $42 \mathrm{veh}$ & $69 \mathrm{veh}$ & $80 \mathrm{~m}$ & $258 \mathrm{~s}$ & $42 \mathrm{~s}$ \\
\hline
\end{tabular}




\begin{tabular}{|c|c|c|c|c|c|c|c|c|}
\hline 07:50-07:55 & 4 veh & 50 veh & $800 \mathrm{~m}$ & 48 veh & 49 veh & $60 \mathrm{~m}$ & $243 \mathrm{~s}$ & $57 \mathrm{~s}$ \\
\hline 07:55-08:00 & $5 \mathrm{veh}$ & 67 veh & $500 \mathrm{~m}$ & 44 veh & 83 veh & $150 \mathrm{~m}$ & $170 \mathrm{~s}$ & $130 \mathrm{~s}$ \\
\hline 08:00-08:05 & 8 veh & 57 veh & $910 \mathrm{~m}$ & 48 veh & 80 veh & $130 \mathrm{~m}$ & $150 \mathrm{~s}$ & $150 \mathrm{~s}$ \\
\hline 08:05-08:10 & 7 veh & 60 veh & $620 \mathrm{~m}$ & 37 veh & 74 veh & $135 \mathrm{~m}$ & $150 \mathrm{~s}$ & $150 \mathrm{~s}$ \\
\hline 08:10-08:15 & 4 veh & 44 veh & $400 \mathrm{~m}$ & 42 veh & 72 veh & $155 \mathrm{~m}$ & $182 \mathrm{~s}$ & $118 \mathrm{~s}$ \\
\hline 08:15-08:20 & 7 veh & 53 veh & $665 \mathrm{~m}$ & 41 veh & 63 veh & $150 \mathrm{~m}$ & $175 \mathrm{~s}$ & $125 \mathrm{~s}$ \\
\hline 08:20-08:25 & 5 veh & 65 veh & $490 \mathrm{~m}$ & 50 veh & 86 veh & $125 \mathrm{~m}$ & $160 \mathrm{~s}$ & $140 \mathrm{~s}$ \\
\hline 08:25-08:30 & 6 veh & 64 veh & $535 \mathrm{~m}$ & 44 veh & 67 veh & $135 \mathrm{~m}$ & $160 \mathrm{~s}$ & $140 \mathrm{~s}$ \\
\hline 08:30-08:35 & 5 veh & 57 veh & $440 \mathrm{~m}$ & 44 veh & 57 veh & $70 \mathrm{~m}$ & $160 \mathrm{~s}$ & $140 \mathrm{~s}$ \\
\hline 08:35-08:40 & 6 veh & 57 veh & $420 \mathrm{~m}$ & 53 veh & 45 veh & $50 \mathrm{~m}$ & $160 \mathrm{~s}$ & $140 \mathrm{~s}$ \\
\hline 08:40-08:45 & 6 veh & $71 \mathrm{veh}$ & $220 \mathrm{~m}$ & 39 veh & $55 \mathrm{veh}$ & $50 \mathrm{~m}$ & $160 \mathrm{~s}$ & $140 \mathrm{~s}$ \\
\hline \multicolumn{9}{|c|}{ October 8th } \\
\hline 07:10-07:15 & 6 veh & 37 veh & $620 \mathrm{~m}$ & 29 veh & 77 veh & $65 \mathrm{~m}$ & $218 \mathrm{~s}$ & $83 \mathrm{~s}$ \\
\hline 07:15-07:20 & 5 veh & 43 veh & $650 \mathrm{~m}$ & 35 veh & 88 veh & $70 \mathrm{~m}$ & $218 \mathrm{~s}$ & $83 \mathrm{~s}$ \\
\hline 07:20-07:25 & 6 veh & 40 veh & $650 \mathrm{~m}$ & 31 veh & 91 veh & $150 \mathrm{~m}$ & $206 \mathrm{~s}$ & $94 \mathrm{~s}$ \\
\hline 07:25-07:30 & 6 veh & 57 veh & $720 \mathrm{~m}$ & 44 veh & 94 veh & $160 \mathrm{~m}$ & $195 \mathrm{~s}$ & $105 \mathrm{~s}$ \\
\hline 07:30-07:35 & 7 veh & 35 veh & $580 \mathrm{~m}$ & 28 veh & 109 veh & $160 \mathrm{~m}$ & $121 \mathrm{~s}$ & $179 \mathrm{~s}$ \\
\hline 07:35-07:40 & 6 veh & 58 veh & $950 \mathrm{~m}$ & 43 veh & 118 veh & $175 \mathrm{~m}$ & $115 \mathrm{~s}$ & $185 \mathrm{~s}$ \\
\hline 07:40-07:45 & 7 veh & 60 veh & $920 \mathrm{~m}$ & 48 veh & 127 veh & $180 \mathrm{~m}$ & $99 \mathrm{~s}$ & $201 \mathrm{~s}$ \\
\hline 07:45-07:50 & 5 veh & 48 veh & $830 \mathrm{~m}$ & 38 veh & 116 veh & $180 \mathrm{~m}$ & $80 \mathrm{~s}$ & $220 \mathrm{~s}$ \\
\hline 07:50-07:55 & 6 veh & 54 veh & $860 \mathrm{~m}$ & 46 veh & 112 veh & $185 \mathrm{~m}$ & $61 \mathrm{~s}$ & $239 \mathrm{~s}$ \\
\hline 07:55-08:00 & 5 veh & 62 veh & $910 \mathrm{~m}$ & 52 veh & 102 veh & $165 \mathrm{~m}$ & $52 \mathrm{~s}$ & $248 \mathrm{~s}$ \\
\hline 08:00-08:05 & 5 veh & 65 veh & $1000 \mathrm{~m}$ & 52 veh & 88 veh & $115 \mathrm{~m}$ & $56 \mathrm{~s}$ & $244 \mathrm{~s}$ \\
\hline 08:05-08:10 & 6 veh & 56 veh & $1100 \mathrm{~m}$ & 42 veh & 103 veh & $160 \mathrm{~m}$ & $58 \mathrm{~s}$ & $242 \mathrm{~s}$ \\
\hline \multicolumn{9}{|c|}{ November 17th } \\
\hline 07:50-07:55 & 7 veh & 64 veh & $680 \mathrm{~m}$ & 49 veh & 74 veh & $70 \mathrm{~m}$ & $155 \mathrm{~s}$ & $145 \mathrm{~s}$ \\
\hline 07:55-08:00 & 7 veh & 75 veh & $768 \mathrm{~m}$ & 59 veh & 73 veh & $70 \mathrm{~m}$ & $165 \mathrm{~s}$ & $135 \mathrm{~s}$ \\
\hline 08:00-08:05 & 8 veh & 53 veh & $700 \mathrm{~m}$ & 42 veh & 90 veh & $50 \mathrm{~m}$ & $152 \mathrm{~s}$ & $148 \mathrm{~s}$ \\
\hline 08:05-08:10 & 9 veh & 52 veh & $905 \mathrm{~m}$ & 40 veh & 97 veh & $70 \mathrm{~m}$ & $128 \mathrm{~s}$ & $172 \mathrm{~s}$ \\
\hline 08:10-08:15 & 7 veh & 51 veh & $790 \mathrm{~m}$ & 40 veh & 95 veh & $60 \mathrm{~m}$ & $110 \mathrm{~s}$ & $190 \mathrm{~s}$ \\
\hline 08:15-08:20 & 8 veh & 63 veh & $1000 \mathrm{~m}$ & 55 veh & 73 veh & $150 \mathrm{~m}$ & $125 \mathrm{~s}$ & $175 \mathrm{~s}$ \\
\hline 08:20-08:25 & 7 veh & 70 veh & $835 \mathrm{~m}$ & 52 veh & 78 veh & $170 \mathrm{~m}$ & $148 \mathrm{~s}$ & $152 \mathrm{~s}$ \\
\hline 08:25-08:30 & 5 veh & 76 veh & $505 \mathrm{~m}$ & 55 veh & 49 veh & $130 \mathrm{~m}$ & $170 \mathrm{~s}$ & $130 \mathrm{~s}$ \\
\hline 08:30-08:35 & 7 veh & 71 veh & $650 \mathrm{~m}$ & 48 veh & 64 veh & $135 \mathrm{~m}$ & $193 \mathrm{~s}$ & $107 \mathrm{~s}$ \\
\hline 08:35-08:40 & 5 veh & 63 veh & $60 \mathrm{~m}$ & 41 veh & 79 veh & $160 \mathrm{~m}$ & $215 \mathrm{~s}$ & $85 \mathrm{~s}$ \\
\hline 08:40-08:45 & 4 veh & 59 veh & $45 \mathrm{~m}$ & 36 veh & 66 veh & $130 \mathrm{~m}$ & $237 \mathrm{~s}$ & $63 \mathrm{~s}$ \\
\hline 08:45-08:50 & 6 veh & 43 veh & $95 \mathrm{~m}$ & 32 veh & 66 veh & $45 \mathrm{~m}$ & $250 \mathrm{~s}$ & $50 \mathrm{~s}$ \\
\hline
\end{tabular}

\section{Proposed methods}

In a metering roundabouts system model, the typical transfer function can be considered as shown in figure 2. The optimal detector location and traffic signal of the roundabout model is based on ensuring the minimum queuing length load, while satisfying the dual-objective with minimum queues on controlling and metered approaches. In the roundabout model, the constraint conditions of the objective function are as follows.

(1) The controlling approach objective:

$$
\operatorname{minf} f_{1}=Q_{C o n}\left(x_{1}, x_{2}\right)
$$

Where $Q_{C o n}$ is controlling approach in Equation $1 ; x_{1}, x_{2}$ are the $D L c$ detector location and Pgre green time; $f_{1}$ is the objective function of controlling queuing length.

(2) The metering approach objective:

$$
\operatorname{minf}_{2}=Q_{m e t}\left(x_{1}, x_{2}\right)
$$



length.

Where $Q_{m e t}$ is metering approach in Equation $2 ; f_{2}$ is the objective function of metering queuing

(3) The total queuing goals:

Integrating the two objective functions, the objective function used to identify the function of metering roundabouts system can be calculated as:

$$
\min Y(x)=\min \left[f_{1}\left(P_{1}\right), f_{2}\left(P_{2}\right)\right]
$$

$Y(x)$ is the objective function after integration.

The optimization process is to extract the optimal parameters Pgre, Pred, NL, Vi, Vci, Vs, and DLc, which makes for minimum queue (see Table 2).

Where, the searching area of the coefficients is set according to the experience, Pgre $=160 \sim 258$ seconds, Pred=43 150 seconds, VN=35 71 vehs, VS=45 116 vehs, VcN=4 9 vehs, VCS=28 59 vehs, $\mathrm{V}_{\mathrm{s}}=7$ meters, $\mathrm{DLc}=50 \sim 250$ meters, $\mathrm{PT}_{\mathrm{c}}=4$ Seconds, and $\mathrm{PT}_{\mathrm{m}}=3$ Seconds, NLcon=2 lanes, NLmet=1 lane.

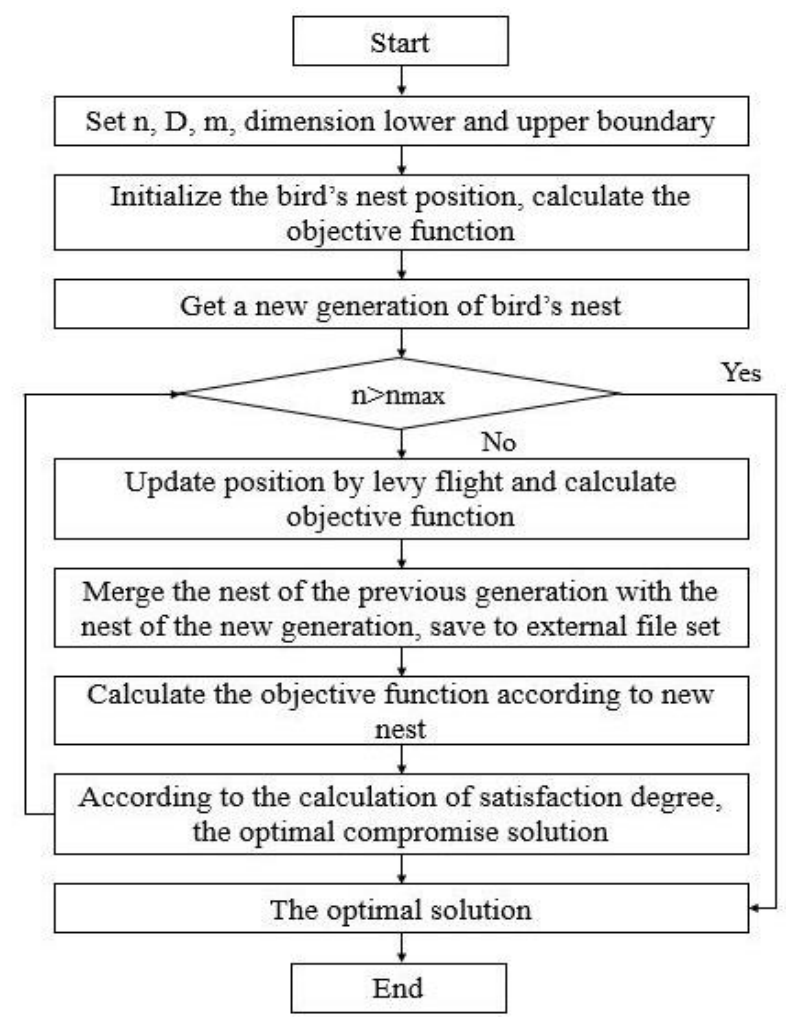

Figure 2. Block diagram of optimize queuing length.

\section{Result and discussion}

This section presents model verification using AIMSUN7 software to compare the optimum detector locations between cuckoo search/local search algorithm and AIMSUN results. In order for metering roundabout modelling, three procedures including modelling, calibration and validation were implemented. Moreover, in order to fit AIMSUN model output to the field data, the GEH statistical test was performed. The GEH statistic, as shown in Equation 21, is a type of chi-squared statistic and used for goodness-of-fit in transport engineering [32,33,34]. If the GEH value is less than five, the model results fit with the observed data well [34,36].

$$
G E H=\sqrt{\frac{(V-E)^{2}}{(E+V)^{/ 2}}}
$$

Where, $E$ is the estimated output by model, and $V$ is the observation.

\subsection{Modelling of Old Belair Road Metering Roundabout}


For the layout modelling, the Old Belair Road roundabout was extracted using the function "template create" in AIMSUN 7 as presented in Figure 3. The current detector was installed on the southern approach at a distance of 115 meters with a traffic signal used on the northern approach for the peak periods.

Queuing lengths on each approach were collected using drones in five-minute intervals in this study and traffic volumes in Table 2 on each approach (Northern approach: VN, Southern approach: VS, Western approach: VW, and Eastern approach: VE) was input for performance evaluation. In order for more precise analysis, 20 minutes of warm-up and cool-off periods were applied before and after the one-hour modelling durations.

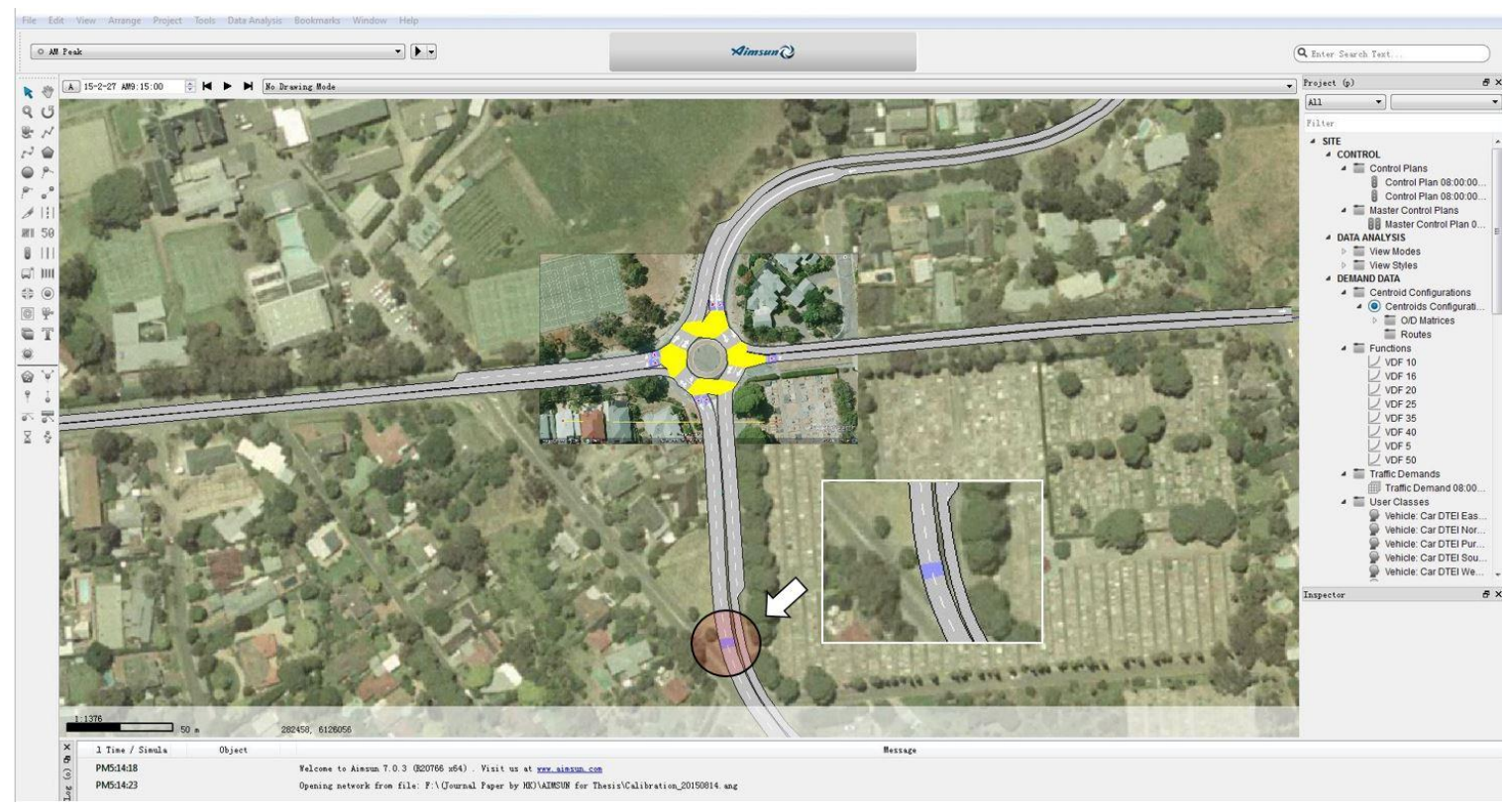

Figure 3. Old Belair Road metering roundabout in AIMSUN 7.

The metering system was set with control strategies under the "traffic management" function in AIMSUN 7, which creates a connection between the installed traffic light and detectors for operating the metering system according to queuing length on the controlling (northern) approach. Start and stop triggers were specified for monitoring the occupancy time in the queue detector zone, as shown in Figure 4.

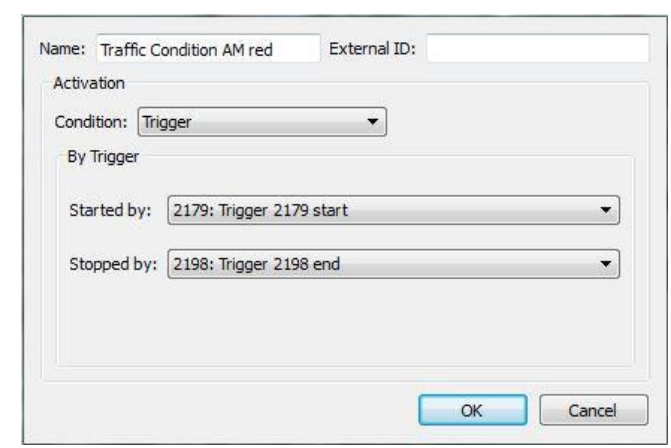

Figure 4. Trigger setting for detector operation.

In addition, the occupancy value can be defined as the "percentage of cycle time that the detector detected presence in the last cycle", as shown in Equation 22.

$$
\text { Occupancy }=\frac{\sum_{i=1}^{\text {Total number of intervals }} t_{\text {final }}(i, \text { cycle })-t_{\text {init }}(i, \text { cycle })}{\text { Cycle }} \times 100
$$


Where, $t_{\text {init }}(i$, cycle $)$ is an initial time, $t_{\text {final }}(i$, cycle $)$ is a final time, and Cycle is 120 seconds.

This study input 55 occupancy value as starting detection and a value of 20 was specified for detection end.

In order to duplicate the real-life signal phase timing and double cycle, two control plans were applied as follows:

- Control Plan 1: Queuing length is shorter than detector location

- Control Plan 2: Queuing length is longer than detector location

Control Plan 1 is for normal conditions which is that vehicle queues did not reach the detector on the controlling approach. In this case, maximum green time (90 seconds: $45+45$ seconds) and minimum green time (42 seconds: $21+21$ seconds) were input (see Table 2). Control Plan 2 is used during metering system activation and if the detector detects the queues on the controlling approach for three seconds, AIMSUN 7 will switch to Control plan 2. When the detector occupancy is cleared, Control plan 1 would be activated automatically.

\subsection{Model Calibration and Validation}

After modelling, parameter calibration is necessary for matching the queuing length from the drone data. This study compared two days queuing length data for the model calibration on October 7 th and $8^{\text {th }}$, and November $17^{\text {th }}$ data was compared for the model validation. Maximum speed (approaching approach and exiting approach), visibility distance, yellow-box speed, maximum desired speed (vehicle) were adjusted as shown in Table 3.

Table 3. Calibrated parameters.

\begin{tabular}{ccc}
\hline Parameters & Default value & Adjusted value \\
\hline $\begin{array}{c}\text { Maximum speed } \\
\text { (approaching) }\end{array}$ & $60 \mathrm{~km} / \mathrm{h}$ & $50 \mathrm{~km} / \mathrm{h}$ \\
\hline Maximum speed (exiting) & $60 \mathrm{~km} / \mathrm{h}$ & $36 \mathrm{~km} / \mathrm{h}$ \\
\hline Visibility distance & $10 \mathrm{~m}$ & $6 \mathrm{~m}($ north), $12 \mathrm{~m}($ south $)$ \\
\hline Yellow-box speed & $10 \mathrm{~km} / \mathrm{h}$ & $4 \mathrm{~km} / \mathrm{h}($ north), $5 \mathrm{~km} / \mathrm{h}(\mathrm{south})$ \\
\hline $\begin{array}{c}\text { Maximum desired vehicle } \\
\text { speed }\end{array}$ & $120 \mathrm{~km} / \mathrm{h}$ & $60 \mathrm{~km} / \mathrm{h}$ \\
\hline
\end{tabular}

With the adjusted values in AIMSUN, the queuing lengths on the controlling and metered approaches were compared in Table 4. It can show that the queuing length of AIMSUN outputs are closely matched to the field data on the north and south approaches during the peak hour.

Table 4. The queuing length comparison between drone data and AIMSUN.

\begin{tabular}{|c|c|c|c|c|c|c|c|c|c|}
\hline \multirow{3}{*}{ Time } & \multicolumn{4}{|c|}{ Oct $7^{\text {th }}$} & \multirow{3}{*}{ Time } & \multicolumn{4}{|c|}{ Oct 8th } \\
\hline & \multicolumn{2}{|c|}{ North } & \multicolumn{2}{|c|}{ South } & & \multicolumn{2}{|c|}{ North } & \multicolumn{2}{|c|}{ South } \\
\hline & $\mathrm{D}(\mathrm{m})$ & $\mathrm{A}(\mathrm{m})$ & $\mathrm{D}(\mathrm{m})$ & $\mathrm{A}(\mathrm{m})$ & & $\mathrm{D}(\mathrm{m})$ & $\mathrm{A}(\mathrm{m})$ & $\mathrm{D}(\mathrm{m})$ & $\mathrm{A}(\mathrm{m})$ \\
\hline 07:45-07:50 & 600 & 520 & 80 & 70 & 07:10-07:15 & 550 & 540 & 70 & 75 \\
\hline 07:50-07:55 & 800 & 740 & 60 & 70 & 07:15-07:20 & 600 & 620 & 60 & 70 \\
\hline 07:55-08:00 & 500 & 530 & 150 & 125 & 07:20-07:25 & 700 & 760 & 90 & 100 \\
\hline 08:00-08:05 & 910 & 950 & 130 & 140 & 07:25-07:30 & 850 & 820 & 140 & 150 \\
\hline 08:05-08:10 & 620 & 630 & 135 & 140 & 07:30-07:35 & 920 & 960 & 150 & 135 \\
\hline 08:10-08:15 & 400 & 450 & 155 & 150 & 07:35-07:40 & 690 & 730 & 160 & 150 \\
\hline 08:15-08:20 & 665 & 700 & 150 & 160 & 07:40-07:45 & 700 & 710 & 155 & 160 \\
\hline 08:20-08:25 & 490 & 510 & 125 & 130 & 07:45-07:50 & 550 & 520 & 140 & 160 \\
\hline 08:25-08:30 & 535 & 565 & 135 & 130 & 07:50-07:55 & 600 & 620 & 150 & 170 \\
\hline 08:30-08:35 & 440 & 395 & 70 & 80 & 07:55-08:00 & 520 & 535 & 150 & 145 \\
\hline 08:35-08:40 & 420 & 390 & 50 & 70 & 08:00-08:05 & 380 & 390 & 80 & 95 \\
\hline 08:40-08:45 & 220 & 250 & 50 & 70 & 08:05-08:10 & 270 & 250 & 60 & 65 \\
\hline
\end{tabular}


${ }^{*} \mathrm{D}=$ Drone data, $\mathrm{A}=$ AIMSUN output

In addition, the GEH test was conducted for model calibration between the drone survey and AIMSUN output. Two days' data (October $7^{\text {th }}$ and $8^{\text {th }}$ ) were used as presented in Table 5 and the GEH values were less than five in all periods. Thus, it can be seen that AIMSUN results fit with drone data well and model calibration was successfully conducted.

Table 5. GEH results for model calibration.

\begin{tabular}{ccccccc}
\hline \multirow{2}{*}{ Statistic } & \multicolumn{3}{c}{ Oct 7th } & \multicolumn{3}{c}{ Oct 8th } \\
\hline \multirow{5}{*}{ Time } & North & South & Time & North & South \\
\cline { 2 - 7 } & $07: 45-07: 50$ & 3.38 & 1.15 & $07: 10-07: 15$ & 0.42 & 0.59 \\
\cline { 2 - 7 } & $07: 50-07: 55$ & 2.16 & 1.24 & $07: 15-07: 20$ & 0.80 & 1.24 \\
\cline { 2 - 7 } & $07: 55-08: 00$ & 1.32 & 2.13 & $07: 20-07: 25$ & 2.22 & 1.03 \\
\cline { 2 - 7 } & $08: 00-08: 05$ & 1.31 & 0.86 & $07: 25-07: 30$ & 1.03 & 0.83 \\
\cline { 2 - 7 } GEH & $08: 05-08: 10$ & 0.40 & 0.42 & $07: 30-07: 35$ & 1.30 & 1.25 \\
\cline { 2 - 7 } & $08: 10-08: 15$ & 2.42 & 0.40 & $07: 35-07: 40$ & 1.50 & 0.80 \\
\cline { 2 - 7 } & $08: 15-08: 20$ & 1.33 & 0.80 & $07: 40-07: 45$ & 0.37 & 0.40 \\
\cline { 2 - 7 } & $08: 20-08: 25$ & 0.89 & 0.44 & $07: 45-07: 50$ & 1.29 & 1.63 \\
\cline { 2 - 7 } & $08: 25-08: 30$ & 1.27 & 0.43 & $07: 50-07: 55$ & 0.81 & 1.58 \\
\cline { 2 - 7 } & $08: 30-08: 35$ & 2.20 & 1.15 & $07: 55-08: 00$ & 0.65 & 0.41 \\
\hline \multirow{2}{*}{\begin{tabular}{c} 
Average \\
\cline { 2 - 7 }
\end{tabular}} & $08: 40-08: 45$ & 1.95 & 2.58 & $08: 05: 05-08: 10$ & 1.24 & 0.63 \\
\hline
\end{tabular}

For model validation, November $17^{\text {th }}$ data was used. Table 6 shows the queuing length of drone and AIMSUN on the north and south approaches in five-minute periods, and the GEH values. Similar to model calibration, the queuing length on the north and south approaches match well and the GEH values are all less than five. Thus, it can be seen that the AIMSUN outputs are reliable.

Table 6. GEH results of model validation.

\begin{tabular}{|c|c|c|c|c|c|c|c|}
\hline \multirow{3}{*}{ Time } & \multicolumn{7}{|c|}{ Nov $17^{\text {th }}$} \\
\hline & \multicolumn{2}{|c|}{ North } & \multicolumn{2}{|c|}{ South } & \multirow{2}{*}{ Statistic } & \multirow{2}{*}{ North } & \multirow{2}{*}{ South } \\
\hline & $\mathrm{D}(\mathrm{m})$ & $\mathrm{A}(\mathrm{m})$ & $\mathrm{D}(\mathrm{m})$ & $\mathrm{A}(\mathrm{m})$ & & & \\
\hline 07:50-07:55 & 680 & 640 & 65 & 70 & \multirow{12}{*}{ GEH } & 1.55 & 0.61 \\
\hline 07:55-08:00 & 770 & 750 & 65 & 80 & & 0.72 & 1.76 \\
\hline 08:00-08:05 & 700 & 650 & 55 & 70 & & 1.92 & 1.90 \\
\hline 08:05-08:10 & 905 & 880 & 65 & 60 & & 0.84 & 0.63 \\
\hline 08:10-08:15 & 790 & 800 & 60 & 70 & & 0.35 & 1.24 \\
\hline 08:15-08:20 & 1005 & 910 & 155 & 160 & & 3.07 & 0.39 \\
\hline 08:20-08:25 & 835 & 725 & 170 & 180 & & 3.94 & 0.75 \\
\hline 08:25-08:30 & 505 & 585 & 130 & 145 & & 3.43 & 1.28 \\
\hline 08:30-08:35 & 650 & 550 & 135 & 160 & & 4.08 & 2.05 \\
\hline 08:35-08:40 & 60 & 85 & 160 & 170 & & 2.93 & 0.78 \\
\hline 08:40-08:45 & 45 & 70 & 130 & 110 & & 3.30 & 1.83 \\
\hline \multirow[t]{2}{*}{ 08:45-08:50 } & 95 & 110 & 45 & 60 & & 1.48 & 2.07 \\
\hline & & & & & $\begin{array}{c}\text { Average } \\
\text { GEH }\end{array}$ & 2.30 & 1.27 \\
\hline
\end{tabular}


In order to find the optimum detector location on November $17^{\text {th }}$, the detector on the controlling approach was moved in 25-meter increments between 50 meters and 225 meters in AIMSUN. Then, the total queuing length (north + south) from 10 replications for peak hour is presented in Table 7.

Table 7. Queuing length on the north and south in accordance with detector moves.

\begin{tabular}{|c|c|c|c|c|c|c|c|c|}
\hline \multirow{2}{*}{ Time } & \multicolumn{2}{|c|}{$\mathrm{DL}=50 \mathrm{~m}$} & \multicolumn{2}{|c|}{$\mathrm{DL}=75 \mathrm{~m}$} & \multicolumn{2}{|c|}{$\mathrm{DL}=100 \mathrm{~m}$} & \multicolumn{2}{|c|}{$\mathrm{DL}=125 \mathrm{~m}$} \\
\hline & $\mathrm{N}(\mathrm{m})$ & $S(m)$ & $\mathrm{N}(\mathrm{m})$ & $S(\mathrm{~m})$ & $\mathbf{N}(\mathbf{m})$ & $\mathrm{S}(\mathrm{m})$ & $\mathbf{N}(\mathbf{m})$ & $S(m)$ \\
\hline 07:50-07:55 & 1,320 & 25 & 820 & 45 & 795 & 60 & 720 & 95 \\
\hline 07:55-08:00 & 1,300 & 30 & 900 & 50 & 850 & 75 & 700 & 115 \\
\hline 08:00-08:05 & 1,250 & 30 & 920 & 50 & 860 & 70 & 820 & 120 \\
\hline 08:05-08:10 & 1,630 & 40 & 920 & 40 & 830 & 80 & 770 & 110 \\
\hline 08:10-08:15 & 2,465 & 40 & 1,330 & 50 & 910 & 100 & 810 & 135 \\
\hline 08:15-08:20 & 2,745 & 45 & 1,680 & 70 & 1,255 & 125 & 860 & 165 \\
\hline 08:20-08:25 & 2,550 & 30 & 1,740 & 80 & 920 & 145 & 700 & 190 \\
\hline 08:25-08:30 & 2,010 & 40 & 1,305 & 50 & 780 & 120 & 570 & 150 \\
\hline 08:30-08:35 & 1,860 & 40 & 1,425 & 60 & 750 & 130 & 555 & 170 \\
\hline 08:35-08:40 & 960 & 30 & 485 & 75 & 180 & 135 & 80 & 175 \\
\hline 08:40-08:45 & 925 & 30 & 425 & 70 & 140 & 100 & 75 & 125 \\
\hline 08:45-08:50 & 900 & 35 & 325 & 50 & 115 & 100 & 75 & 130 \\
\hline Average $(\mathrm{N}+\mathrm{S})$ & \multicolumn{2}{|c|}{1,694} & \multicolumn{2}{|c|}{1,080} & \multicolumn{2}{|c|}{802} & \multicolumn{2}{|c|}{701} \\
\hline \multirow{2}{*}{ Time } & \multicolumn{2}{|c|}{$\mathrm{DL}=150 \mathrm{~m}$} & \multicolumn{2}{|c|}{$\mathrm{DL}=175 \mathrm{~m}$} & \multicolumn{2}{|c|}{$D L=200 m$} & \multicolumn{2}{|c|}{$\mathrm{DL}=225 \mathrm{~m}$} \\
\hline & $\mathbf{N}(\mathbf{m})$ & $S(\mathrm{~m})$ & $\mathrm{N}(\mathrm{m})$ & $S(m)$ & $\mathrm{N}(\mathrm{m})$ & $\mathrm{S}(\mathrm{m})$ & $\mathbf{N}(\mathrm{m})$ & $S(m)$ \\
\hline 07:50-07:55 & 560 & 105 & 430 & 110 & 290 & 135 & 330 & 165 \\
\hline 07:55-08:00 & 580 & 105 & 450 & 125 & 340 & 150 & 380 & 170 \\
\hline 08:00-08:05 & 650 & 110 & 490 & 140 & 460 & 160 & 450 & 190 \\
\hline 08:05-08:10 & 680 & 135 & 510 & 165 & 470 & 185 & 460 & 190 \\
\hline 08:10-08:15 & 700 & 150 & 520 & 180 & 430 & 210 & 500 & 220 \\
\hline 08:15-08:20 & 825 & 190 & 555 & 200 & 480 & 240 & 520 & 255 \\
\hline 08:20-08:25 & 655 & 195 & 660 & 215 & 560 & 225 & 550 & 250 \\
\hline 08:25-08:30 & 520 & 160 & 530 & 185 & 520 & 205 & 500 & 235 \\
\hline 08:30-08:35 & 525 & 160 & 550 & 180 & 520 & 185 & 510 & 220 \\
\hline 08:35-08:40 & 80 & 170 & 80 & 200 & 40 & 230 & 40 & 240 \\
\hline 08:40-08:45 & 80 & 130 & 75 & 150 & 45 & 170 & 45 & 200 \\
\hline 08:45-08:50 & 65 & 130 & 70 & 135 & 45 & 155 & 40 & 195 \\
\hline Average $(\mathrm{N}+\mathrm{S})$ & \multicolumn{2}{|c|}{638} & \multicolumn{2}{|c|}{575} & \multicolumn{2}{|c|}{538} & \multicolumn{2}{|c|}{571} \\
\hline
\end{tabular}

The optimum detector location reflects the minimum queuing length considering both (controlling and metered) approaches. When the detector location is at 50 meters, queuing length of two approaches was on average 1,694 meters for one hour. Thus, the detector location of 50 meters is the worst distance. When the detector location is at 200 meters, the sum of both approaches was on average 538 meters. In this case, queuing length can be decreased by around 1150 meters for peak hour.

\subsection{Best Detector Location in Cuckoo Search/Local Search Algorithm}

In order to verify the proposed optimization algorithm to determine the detector location in accordance with arrival volume and conflicting volume, the two signal timing schemes are obtained 
by using Equation 3, which are respectively recorded as optimize Equation 1 and 2. Furthermore, the tuning parameters for the CS/LS proposed algorithm, Levy exponent $(\beta)=0.25$, number of iterations $=50$, number of nests $=10$ were set in order to get accurate results.

Table 8 shows that each iteration indicates different queuing lengths on the controlling and metered approach in accordance with a relationship between detector locations and phase green time. Total queuing length (controlling + metered approaches) looks steady after 40th iteration, which means 210 meters of detector location is the best detector location.

Table 8. Effect of detector location and signal time.

\begin{tabular}{|c|c|c|c|c|c|c|c|c|c|c|c|}
\hline $\begin{array}{c}\text { No. } \\
\text { Iteration }\end{array}$ & $\begin{array}{l}\text { Pgre } \\
\text { (s) }\end{array}$ & $\begin{array}{c}\text { DLC } \\
\text { (m) }\end{array}$ & $\begin{array}{c}\text { Qcon } \\
\text { (m) }\end{array}$ & $\begin{array}{c}\text { Qmet } \\
\text { (m) }\end{array}$ & $\begin{array}{c}\text { Qtotal } \\
\text { (m) }\end{array}$ & $\begin{array}{c}\text { No. } \\
\text { Iteration }\end{array}$ & $\begin{array}{c}\text { Pgre } \\
\text { (s) }\end{array}$ & $\begin{array}{c}\text { DLC } \\
(\mathrm{m})\end{array}$ & $\begin{array}{c}\text { Qcon } \\
\text { (m) }\end{array}$ & $\begin{array}{c}\text { Qmet } \\
\text { (m) }\end{array}$ & $\begin{array}{c}\text { Qtotal } \\
\text { (m) }\end{array}$ \\
\hline 1 & 180.8 & 57.5 & 46.3 & 1206.6 & 1253.0 & 26 & 190.6 & 196.6 & 166.4 & 324.9 & 491.3 \\
\hline 2 & 203.6 & 55.8 & 50.6 & 1005.5 & 1056.2 & 27 & 210.9 & 147.7 & 138.6 & 351.5 & 490.1 \\
\hline 3 & 178.4 & 73.4 & 58.3 & 964.2 & 1022.5 & 28 & 222.2 & 123.4 & 122.2 & 366.7 & 488.9 \\
\hline 4 & 161.5 & 86.9 & 62.5 & 927.3 & 989.8 & 29 & 176.9 & 245.9 & 193.7 & 291.5 & 485.2 \\
\hline 5 & 182.8 & 77.3 & 62.9 & 883.2 & 946.1 & 30 & 252.9 & 67.1 & 75.6 & 408.5 & 484.0 \\
\hline 6 & 179.5 & 102.3 & 81.8 & 685.7 & 767.5 & 31 & 190.1 & 227.0 & 192.1 & 281.9 & 474.0 \\
\hline 7 & 189.6 & 102.4 & 86.5 & 627.5 & 714.0 & 32 & 211.1 & 165.7 & 155.7 & 312.5 & 468.2 \\
\hline 8 & 183.5 & 112.2 & 91.7 & 604.7 & 696.4 & 33 & 203.6 & 194.2 & 176.0 & 289.1 & 465.2 \\
\hline 9 & 182.6 & 117.0 & 95.2 & 584.1 & 679.2 & 34 & 195.3 & 234.6 & 204.0 & 259.8 & 463.8 \\
\hline 10 & 196.8 & 109.3 & 95.8 & 549.5 & 645.3 & 35 & 237.6 & 102.5 & 108.4 & 354.7 & 463.1 \\
\hline 11 & 168.1 & 151.5 & 113.4 & 506.8 & 620.2 & 36 & 214.7 & 168.9 & 161.5 & 294.0 & 455.5 \\
\hline 12 & 213.3 & 96.3 & 91.4 & 524.4 & 615.8 & & 224.9 & 137.7 & 137.9 & 317.4 & 455.4 \\
\hline 13 & 233.2 & 72.2 & 75.0 & 538.9 & 613.9 & 38 & 241.8 & 97.4 & 104.9 & 348.0 & 452.9 \\
\hline 14 & 195.1 & 147.7 & 128.3 & 413.5 & 541.9 & 39 & 204.7 & 235.7 & 214.8 & 235.5 & 450.3 \\
\hline 15 & 244.4 & 69.7 & 75.9 & 464.1 & 539.9 & 40 & 208.7 & 210.2 & 195.3 & 253.0 & 448.3 \\
\hline 16 & 205.1 & 131.7 & 120.3 & 419.6 & 539.8 & 41 & 208.7 & 210.2 & 195.3 & 253.0 & 448.3 \\
\hline 17 & 228.7 & 94.3 & 96.0 & 440.3 & 536.3 & 42 & 208.7 & 210.2 & 195.3 & 253.0 & 448.3 \\
\hline 18 & 224.8 & 101.6 & 101.7 & 431.2 & 532.8 & 43 & 208.7 & 210.2 & 195.3 & 253.0 & 448.3 \\
\hline 19 & 177.1 & 185.9 & 146.6 & 385.0 & 531.6 & 44 & 208.7 & 210.2 & 195.3 & 253.0 & 448.3 \\
\hline 20 & 178.9 & 192.2 & 153.1 & 366.9 & 520.0 & 45 & 208.7 & 210.2 & 195.3 & 253.0 & 448.3 \\
\hline 21 & 197.9 & 159.3 & 140.4 & 373.3 & 513.6 & 46 & 208.7 & 210.2 & 195.3 & 253.0 & 448.3 \\
\hline 22 & 164.3 & 230.9 & 168.9 & 342.2 & 511.1 & 47 & 208.7 & 210.2 & 195.3 & 253.0 & 448.3 \\
\hline 23 & 222.6 & 113.7 & 112.7 & 396.5 & 509.2 & 48 & 208.7 & 210.2 & 195.3 & 253.0 & 448.3 \\
\hline 24 & 215.0 & 129.1 & 123.6 & 383.4 & 507.0 & 49 & 208.7 & 210.2 & 195.3 & 253.0 & 448.3 \\
\hline 25 & 183.0 & 209.2 & 170.5 & 325.5 & 496.0 & 50 & 208.7 & 210.2 & 195.3 & 253.0 & 448.3 \\
\hline
\end{tabular}

Figure 5 shows the total queuing length for optimization arrived at for different detector locations and signal times. Optimizations from Equations 1 and 2 are calculated based on collected traffic flow. From the $1^{\text {st }}$ to $13^{\text {th }}$ iteration, the queuing length on metered approach is decreased dramatically by 55.3 percent (from 1,206 meters to 539 meters). The queuing length on the controlling approach, however, is slightly increased by 30 meters. Thus, the total queuing (controlling + metered) length is 613.9 meters for one hour (51 percent decrease). On the other hand, there is not much difference between the $14^{\text {th }}$ and $40^{\text {th }}$ iterations and the gap in the total queuing length is only 93.6 
meters an hour. It can be seen that as the iteration is repeated, the queuing length on the controlling approach is increased while the queuing length on the metered approach is decreased. The total queuing length cannot be changed after the $40^{\text {th }}$ iteration by CS/LS algorithm, which means detector location at 210 meters is the optimal queuing length on the controlling and metered approaches.

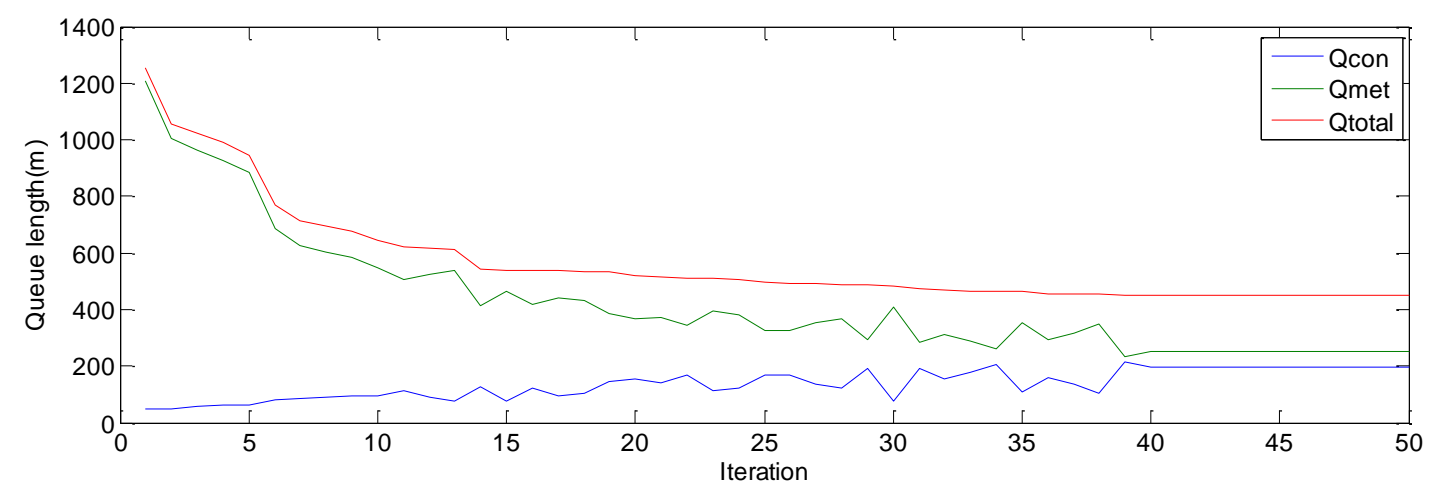

Figure 5. Optimizing the location and Green time signal of Total queuing length.

Figure 6 illustrates a relationship between detector location and signal green time with iteration increases in CS/LS algorithm (left-side y axis is detector location and right-side y axis is signal green time). Each iteration finds the best phase green time to minimize the queuing length on the controlling and metered approaches. The $30^{\text {th }}$ iteration indicates that the maximum green time, detector location and total queuing length are 252 seconds, 67 meters and 484 meters respectively. In addition, 208 seconds of phase green time, 210 meters of detector location indicate the optimal roundabout operation.

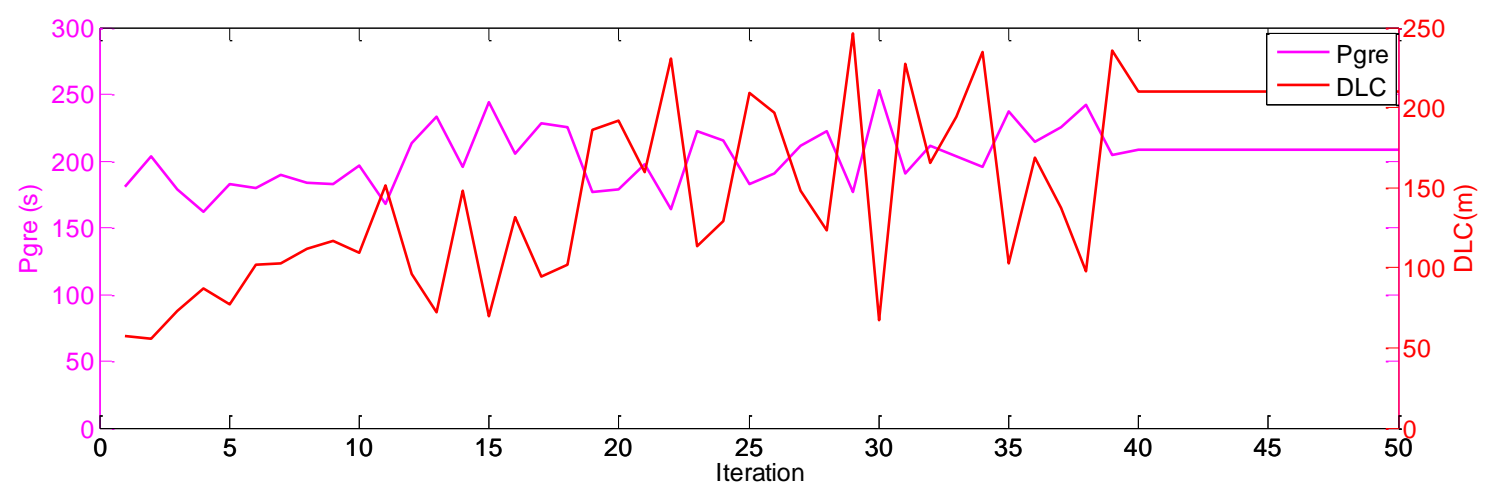

Figure 6. Relationship between detector location and signal green time.

\subsection{Comparisons}

The optimum detector under a variety of traffic conditions at a metering roundabout is calculated and simulated by CS/LS algorithm and AIMSUN software based on November $17^{\text {th }}$ data. Table 9 shows that the result of the proposed algorithm obtained by adopting the best detector location makes the average queuing length decrease by $6.8 \%$ compared to AIMSUN. The best detector location attained from the CS/LS algorithm is 209 meters and the total queueing length is 499 meters, whereas, AIMSUN simulates that 200 meters of detector location can minimize the total queuing length by 538 meters. In addition, phase green time, average queuing length on the controlling approach, average queuing length on the metered approach match 90.3 percent, 91.7 percent and 96.1 percent respectively between the two models.

Table 9. Comparison of proposed method. 


\begin{tabular}{llll}
\hline & AIMSUN software & $\begin{array}{l}\text { CS/LS } \\
\text { Algorithm }\end{array}$ & Ratio \\
\hline Pgre & $217 \mathrm{~s}$ & $247 \mathrm{~s}$ & $87.8 \%$ \\
\hline DLC & $200 \mathrm{~m}$ & $209 \mathrm{~m}$ & $95.7 \%$ \\
\hline Qcon & $187 \mathrm{~m}$ & $175 \mathrm{~m}$ & $91.7 \%$ \\
\hline Qmet & $350 \mathrm{~m}$ & $324 \mathrm{~m}$ & $96.1 \%$ \\
\hline Qtotal & $538 \mathrm{~m}$ & $499 \mathrm{~m}$ & $93.2 \%$ \\
\hline
\end{tabular}

The research result indicates that there is not much difference in detector location between CS/LS algorithm and AIMSUN software. Although the total queuing length of the two models is similar (7 percent), phase green time and queuing length on each approach is slightly different (12 percent).

\section{Conclusion}

This paper attempts to investigate the optimal detector location at the Old Belair Road metering roundabout using CS/LS algorithm in order to minimize the queuing length not only on the controlling, but also on the metered approaches. The outputs were compared with the microscopic simulation model AIMSUN as algorithm verification. The CS/LS algorithm indicated that detector location at 209 meters optimizes the queuing length on the controlling approach (204 meters) and metered approach (364 meters). Moreover, 247 seconds of average phase green time was calculated for the one-hour morning peak. It is quite similar to the AIMSUN model output and the differences are just nine meters in detector location and 30 seconds in phase green time. Thus, it can be expected that the CS/LS algorithm model used in this paper would save time for determining the best detector location at metering roundabouts. Furthermore, the proposed model would serve as a platform for studying the relationship between detector locations and signal phase time at metering roundabouts. Some limitations in the research are recognized, however, and could be enhanced by more comprehensive research. First, a short lane was considered as one lane and the constant " 1 " was applied to the queuing models, but a specific constant needs to be defined in accordance with the length of the short lane. Second, in order for a more accurate model output, more varied conditions need to be considered such, as different geometry and traffic volume.

Author Contributions: Hong Ki An arranged the whole paper writing: including conceptualization, data collection, aimsun analysis, writing original draft preparation; Liu Yao analyzed data in CL/LS algorithm; Dong Sun Kim contributed valuable ideas of improving the research and writing-review and editing.

Funding: This research received no external funding.

Acknowledgments: The authors would like to thank Dr. Ahmed N Abdalla for his great advice on CS/LS algorithm development in this study, and University of South Australia for providing aimsun software for network analysis.

Conflicts of Interest: The authors declare no conflict of interest.

\section{References}

1. Stevens, CR. Signals and Meters at Roundabouts. Paper presented at the 2005 Mid-Continent Transportation Research Symposium, Ames, Iowa, 2005.

2. Akçelik, R. Roundabout metering signals: capacity, performance and timing. Procedia-Social and Behavioral Sciences. 2011, 16, 686-696.

3. Hummer, JE.; Milazzo, I.; Joseph, S.; Schroeder, B.; Salamadi, K. The Potential for Metering to Help Roundabouts Manage Peak Period Demands in the US. Transportation Research Board 93rd Annual Meeting, Washington D.C, USA, 2014. 
4. An, H.K.; Yue, W.L.; Stazic B. Dual Signals Roundabout Evaluation in Adelaide using SIDRA and AIMSUN Modelling software, Road and Transport Research. 2017, Volume 26, pp. 36-49.

5. Krivda, V.; Petru, J.; Macha, D.; Plocova, K.; Fibich, D. An Analysis of Traffic Conflicts as a Tool for Sustainable Road Transport. Sustainability 2020, 12, 7198

6. Hagring, O. Effects of OD flows on roundabout entry capacity. In Proceedings of the 4th International Symposium on Highway Capacity, Maui, Hawaii, USA, 2000.

7. Krogscheepers, J.; Roebuck, C. Unbalanced traffic volumes at roundabouts. In Proceedings of the 4th International Symposium on Highway Capacity, Transportation Research Circular E-C018, Maui, Hawaii, 2000, 446-458.

8. Akçelik, R.; Chung, E.; Besley, M. Performance of roundabouts under heavy demand conditions. Road and Transport Research, 1996, 5: 36-57.

9. Akçelik, R. Roundabouts with unbalanced flow patterns. ITE 2004 Annual Meeting, Hawaii. USA, 2004.

10. Akçelik, R. Capacity and performance analysis of roundabout metering signals. TRB National Roundabout Conference, Vail, Colorado, USA, 2005, 22-25.

11. Fortuijn, L. Robustness of roundabout metering systems (RMS). In Proceedings of the 4th international roundabout conference, Transportation Research Board, 16-18 April 2014, Seattle, USA.

12. Lyapin, S.; Rizaeva, Y.; Kadasev, D.; Sysoe, A. Methods to Analyze Traffic Demand Formation in Intelligent Transportation and Logistic Regional Network. Transportation Research Procedia, 2020, 45, 522-529.

13. Yua, H.; Ma, R.; Zhang, H.M. Optimal traffic signal control under dynamic user equilibrium and link constraints in a general network. Transportation Research Part B: Methodological, 2018, 110, 302-325.

14. Brederode, L.; Verlinden, K. Travel demand matrix estimation methods integrating the full richness of observed traffic flow data from congested networks. Transportation Research Procedia, 2019, 42, 19-31.

15. Lin, S.; Pan, T.L.; Lam, W.H.K.; Zhong, R.X.; Schutter, B.D. Stochastic Link Flow Model for Signalized Traffic Networks with Uncertainty in Demand. IFAC-Papers OnLine, 2018, 51, 458-463.

16. Ding, Z.J.; Dai, Z.; Chen, X.M.; Jiang R. Simulating on-demand ride services in a Manhattan-like urban network considering traffic dynamics. Physica A: Statistical Mechanics and its Applications, 2020, 545, 123621.

17. Fontaine, P.; Minner, S. A dynamic discrete network design problem for maintenance planning in traffic networks. Annals of Operations Research, 2017, 253, 757-772

18. Sofronova, E.A.; Belyakov, A.A.; Khamadiyarov, D.B. Optimal Control for Traffic Flows in the Urban Road Networks and Its Solution by Variational Genetic Algorithm. Procedia Computer Science, 2019, 150, 302-308.

19. Celtek, S.A.; Durdu, A.; All, M.E. Real-time traffic signal control with swarm optimization methods. Measurement, 2020, 166, 108206.

20. An, H.K.; Abdalla, A.N. Prediction of queuing length at metering roundabout using adaptive neuro fuzzy inference system. Measurement and Control, 2019, 52, 432-440. 
21. Azhar, A.M.; Svante, B. Signal Control of Roundabouts. Procedia-Social and Behavioral Sciences, 2011, 16, 729738.

22. Mosslemi, M. Using Metering Signals at Roundabouts with Unbalanced Flow Patterns to Improve the Traffic Condition: The Case Study of Kannik Area in Stavanger. Master Thesis, Linköping University, Department of Science and Technology, Norrköping, Sweden, 2008.

23. Akçelik, R. Analysis of Roundabout Metering Signals. Paper presented at the 25th AITPM National Conference, Melbourne, Australia, 2006.

24. An, H.K.; Yue, W.L.; Stazic, B. Estimation of Vehicle Queuing Lengths at Metering Roundabouts. Journal of Traffic and Transportation Engineering (English Edition), 2017, 4, 545-554.

25. Bin, S.; Cui, Z.; Dai, C.; Chen, W. DV-Hop Localization Algorithm with Cuckoo Search. Sensor Letters, 2014,12, 444-447.

26. Zhang, M. Hybrid multi-objective cuckoo search with dynamical local search. Memetic Computing, 2017, 10, $1-10$.

27. Cao, Y.; Zhang, H.; Li, W.; Zhou, M.; Zhang, Y.; Chaovalitwongse, W.A. Comprehensive learning particle swarm optimization algorithm with local search for multimodal functions, IEEE Transactions on Evolutionary Computation, 2018, 23, 718-731.

28. Xu, Y.; Qu, R.; Renfa, L. A simulated annealing based genetic local search algorithm for multi-objective multicast routing problems, Annals of Operations Research, 2013, 206, 527-555.

29. Soliman, O.S.; Elgendi, E.A. A hybrid estimation of distribution algorithm with random walk local search for multimode resource-constrained project scheduling problems. International Journal of Computer Trends and Technology, 2014, 8, 57-64.

30. Slavin, C.; Feng, W.; Figliozzi, M.; Koonce, P. Statistical study of the impact of adaptive traffic signal control on traffic and transit performance. Transportation Research Record. 2013, 2356, 117-26.

31. Suksri, C. ANALYSIS AND APPLICATION OF TRAFFIC SIGNAL CONTROL DATA. Ph.D. Thesis, University of South Australia, Department of Transport System Engineering, Adelaide, South Australia, 2012.

32. Dewees, D.N. Estimating the time costs of highway congestion. Econometrica: Journal of the Econometric Society, 1979, 1499-1512.

33. Paz, A.; Molano, V.; Gaviria, C. Calibration of corsim models considering all model parameters simultaneously. Proceedings of the 15th International IEEE Conference on Intelligent Transportation Systems, IEEE, 16-22 September 2012, Anchorage, USA.

34. Vasconcelos, L.; Silva, A.B.; Seco, A.; Silva, J. Estimating the parameters of Cowan's M3 headway distribution for roundabout capacity analyses. The Baltic Journal of Road and Bridge Engineering. 2012, 7, 261-8.

35. Feldman, O. The GEH Measure and Quality of the Highway Assignment Models, Association for European Transport and Contributors, London. UK, 2012, 1-18. 
36. Vuk, G.; Hansen, C.O. Validating the passenger traffic model for Copenhagen, Transportation, 2006, 33, 371392. 